Article

\title{
Effect of Waveform and Heat Treatment Processes on the Performance of Electrodeposited Co-P Coating
}

\author{
Xiaomei Chen, Jiangang Qian * and Xiaotian $\mathrm{Hu}$ \\ School of Chemistry \& Environment, Beihang University, Beijing 100191, China; chemcxm@163.com (X.C.); \\ huxiaotian92@163.com (X.H.) \\ * Correspondence: qianjg@buaa.edu.cn; Tel.: +86-10-8233-9870
}

Received: 3 March 2017; Accepted: 5 September 2017; Published: 15 September 2017

\begin{abstract}
Cobalt-phosphorus (Co-P) alloy is a promising material for the replacement of traditional hard chromium alloy of high hardness. In this paper, the cobalt-phosphorus alloy layer with high phosphorus content was formed by electrodeposition in a cobalt sulfate solution system under direct current (DC), single pulse (SP) current and double pulse (DP) current, separately. Surface morphology, structure and properties of the deposited layer were characterized by scanning electron microscopy (SEM), transmission electron microscopy (TEM), X-ray diffraction (XRD), differential scanning calorimetry (DSC), Vickers microhardness and a neutral salt spray test, respectively. The results showed that the dense Co-P coatings could be obtained by DC, SP and DP with P content of 9.6, 8.9 and $9.1 \mathrm{wt} \%$, respectively. After $30 \mathrm{~min}$ heat treatment at $400{ }^{\circ} \mathrm{C}$, coatings deposited under DC, SP and DP currents transformed from an amorphous to a nanocrystalline state, while the grain size was $12-13 \mathrm{~nm}, 10-12 \mathrm{~nm}$ and $8-10 \mathrm{~nm}$, respectively. Among all these conditions, the microhardness of coatings deposited under DP current was the highest, which was $1211 \mathrm{HV}$, while the microhardness of coatings deposited under DC current was the lowest but higher than that of hard chromium. The wear rate of Co-P coatings was $4 \times 10^{-6}-5 \times 10^{-6} \mathrm{~mm}^{3} / \mathrm{N}$ m with $\mathrm{Si}_{3} \mathrm{~N}_{4}$ ball as bearing material, which was lower than that of hard chromium. In coatings deposited under different currents with a thickness of ca. $40 \mu \mathrm{m}$, no visible corrosion area appeared after $1000 \mathrm{~h}$ of a neutral salt spray test. Coatings heated at 300 and $400{ }^{\circ} \mathrm{C}$ reached the corrosion grade 7 and grade $4-5$, respectively after $1000 \mathrm{~h}$ of a neutral salt spray test, so the wear resistance of Co-P coatings was better than that of hard chromium.
\end{abstract}

Keywords: cobalt phosphorus alloy; hard coating; electrodeposition; heat treatment; neutral salt spray test

\section{Introduction}

Hard chromium deposits have been used as a protective coating for decades due to their excellent properties of high hardness and wear resistance. Since the environmental factor has become a prior consideration in both technology and industry, hard chromium deposition has been banned in some developed countries, due to the fact that $\mathrm{Cr}$ (VI) in chromic acid solution used for chromium deposition is known to be carcinogenic and detrimental to the environment [1]. In order to solve this problem, researchers are looking for promising materials such as Ni-P, Ni-Co-P, and Co-P to replace hard chromium [2-6]. Among which, cobalt-phosphorus (Co-P) alloy coatings have received much attention due to their high hardness, good wear resistance, low friction coefficient and high thermal stability $[1,7]$. Therefore, Co-P alloy coatings are becoming a promising alternative to hard chromium coatings [8].

The major properties of Co-P coatings and the plating process thereof have been studied by many researchers. Studies on the effect of $\mathrm{pH}$ and surfactant on properties of the electrodeposited Co-P coatings were carried out by Zeinali-Rad et al. [9]. The results showed that $\mathrm{P}$ content of the 
coatings increased with the rising $\mathrm{pH}$ of the solution from 1 to 4 , while the microhardness values decreased, and the highest hardness value was $600 \mathrm{HV}$. It has been demonstrated that a certain amount of surfactant in solution could result in more smooth coatings. Ezhilselv et al. [10] measured the potentiodynamic polarization curve of Co-P coatings, which revealed that coatings deposited under pulse current showed better corrosion resistance than that deposited under direct current. A similar result was obtained by Kosta et al. [11]. On the other hand, da Silva et al. [12] found that $\mathrm{P}$ was distributed heterogenetically in nanocrystalline Co-P coatings which contained 1.1-3.2 wt \% $\mathrm{P}$, and $\mathrm{P}$ segregated to the grain boundaries after annealing, thereby the microhardness of the alloy layer was improved significantly. Choi [13] discovered that $\mathrm{Co}_{2} \mathrm{P}$ and $\mathrm{CoP}$ precipitates formed in grain boundaries during the annealing process. Kosta $[11,14]$ found that the grain size of the Co-P coatings deposited under single pulse current was obviously smaller than that deposited under direct current. They also concluded that the corrosion resistance of the Co-P alloy layer was better than that of the hard chrome layer from the potentiodynamic polarization curve, however, the corrosion resistance degraded severely after annealing at $400{ }^{\circ} \mathrm{C}$. Some works $[1,9,15,16]$ suggest that heat treatment could improve the microhardness of the Co-P alloy. After heat treatment for $10 \mathrm{~min}$ at $400{ }^{\circ} \mathrm{C}$, the microhardness of the Co-P alloy could rise to 1000-1100 HV, while the hardness of hard chromium was usually 900-1000 HV.

Based on the studies above, the overall performance of Co-P coatings deposited under a single pulse current is better than that of Co-P coatings deposited under a direct current, and the heat treatment process exerted great influence on the performance of Co-P coatings which means the performance of Co-P coatings is partly affected by the deposition current waveform, while it is closely related to the heat treatment process. In this work, the effects of direct current (DC), single pulse (SP), double pulse (DP) and different heat treatment processes on the performance of Co-P coatings were systematically studied, with the aim to replace hard chromium.

\section{Materials and Methods}

Carbon steel was used as a cathode for electrodeposition, the composition and mechanical properties are as follows: Component (\%), C: $0.42-0.50, \mathrm{Cr}: \leq 0.25, \mathrm{Mn}: 0.50-0.80, \mathrm{Ni}: \leq 0.25, \mathrm{P}: \leq 0.035$, S: $\leq 0.035$, Si: $0.17-0.37$; mechanical properties: $\sigma_{\mathrm{b}}: \geq 600 \mathrm{MPa}, \sigma_{\mathrm{s}}: \geq 355 \mathrm{MPa}, \delta_{5}: \geq 16 \%, \psi: \geq 40 \%$, hardness: $\leq 197 \mathrm{HB}$. The substrates with an area of $30 \times 20 \mathrm{~mm}^{2}$ were abraded with different grades of SiC emery papers ranged from 600\# to 2000\#. These specimens were then electrolyzed as the anode at a current density of $6 \mathrm{~A} \mathrm{dm}^{-2}$ in an alkaline solution for degreasing. The following solution was used: $\mathrm{NaOH} 40 \mathrm{~g} \mathrm{~L}^{-1}, \mathrm{Na}_{2} \mathrm{CO}_{3} 35 \mathrm{~g} \mathrm{~L}^{-1}, \mathrm{Na}_{3} \mathrm{PO}_{4} \cdot 12 \mathrm{H}_{2} \mathrm{O} 30 \mathrm{~g} \mathrm{~L}^{-1}, \mathrm{Na}_{2} \mathrm{SiO}_{3} 5 \mathrm{~g} \mathrm{~L}^{-1}$. (NaOH, AR, Beijing Chemical Works, Beijing, China; $\mathrm{Na}_{2} \mathrm{CO}_{3}$, AR, Beijing Chemical Works; $\mathrm{Na}_{3} \mathrm{PO}_{4} \cdot 12 \mathrm{H}_{2} \mathrm{O}$ AR, Beijing Chemical Works; $\mathrm{Na}_{2} \mathrm{SiO}_{3}, \mathrm{AR}$, Beijing Chemical Works.) Finally, the specimens were washed in $5 \% \mathrm{H}_{2} \mathrm{SO}_{4}$ (AR, Beijing Chemical Works) solution for $30 \mathrm{~s}$ and rinsed with deionized water.

Co-P coatings were deposited under DC, SP and DP, separately. Basic composition of the electroforming solution was comprised of $\mathrm{CoSO}_{4} \cdot 7 \mathrm{H}_{2} \mathrm{O}$ (AR, Tianjin Guangfu Fine Chemical Research Institute, Tianjin, China), $\mathrm{CoCl}_{2} \cdot 6 \mathrm{H}_{2} \mathrm{O}$ (AR, Tianjin Guangfu Fine Chemical Research Institute), $\mathrm{H}_{3} \mathrm{PO}_{3}$ (AR, Sinopharm Chemical Reagent Co., Ltd., Shanghai, China), $\mathrm{H}_{3} \mathrm{BO}_{3}$ (AR, Beijing Chemical Works), carbamide (AR, Xilong Chemical Co., Ltd., Shantou, China), $\mathrm{NH}_{4} \mathrm{Cl}$ (AR, Beijing Chemical Works). The $\mathrm{pH}$ of the solution was adjusted to $1.2-2.2$ by the addition of $\mathrm{H}_{2} \mathrm{SO}_{4}$. The electrodepositing parameters are listed in Table 1. Co-P coatings were deposited for $2 \mathrm{~h}$ to obtain the thickness of 40-50 $\mu \mathrm{m}$. After deposition, the samples were washed with deionized water and dried in the air. The direct current was provided by DC voltage and a current stabilized power supply (DH1719A-2, Beijing Dahua Radio Equipment Plate, Beijing, China), pulse current was provided by double pulse voltage and a current stabilized power supply (SOYI 50010, Shanghai SOYI power system equipment Co., Ltd., Shanghai, China).

Co-P coatings were heated in the vacuum for $30 \mathrm{~min}$ at 200,300 and $400{ }^{\circ} \mathrm{C}$, respectively, with the heating rate of $6^{\circ} \mathrm{C} / \mathrm{min}$ below $100 \mathrm{~Pa}$. 
Table 1. Deposition parameters.

\begin{tabular}{|c|c|c|c|}
\hline \multirow{2}{*}{ Parameter } & \multicolumn{3}{|c|}{ Value } \\
\hline & DC & SP & DP \\
\hline $\mathrm{j}_{\text {peak }}^{+}\left(\mathrm{A} \mathrm{dm}{ }^{-2}\right)$ & 5 & +50 & +50 \\
\hline Positive duty cycle & - & $10 \%$ & $10 \%$ \\
\hline $\mathrm{j}^{-}$peak $\left(\mathrm{A} \mathrm{dm} \mathrm{d}^{-2}\right)$ & - & - & -5 \\
\hline Negative duty cycle & - & - & $5 \%$ \\
\hline Frequence & - & $5000 \mathrm{~Hz}$ & $5000 \mathrm{~Hz}$ \\
\hline Temperature & \multicolumn{3}{|c|}{$50{ }^{\circ} \mathrm{C}$} \\
\hline Anode & \multicolumn{3}{|c|}{ Co plate $(\mathrm{Co}>99 \%)$} \\
\hline $\mathrm{pH}$ & \multicolumn{3}{|c|}{$1.2-2.2$} \\
\hline
\end{tabular}

The surface morphology of Co-P coatings was observed by SEM. Grain size was characterized by TEM. Phase structure was inspected by XRD. Microhardness was tested by Vickers microhardness tester (FUTURE-TECH, Japan). Wear rate was tested by a linear reciprocating friction tester Bruker, America), with the loading of $5 \mathrm{~N}$, bearing material of $4 \mathrm{~mm} \mathrm{Si}_{3} \mathrm{~N}_{4}$ ball, frequency of $5 \mathrm{~Hz}$, and a total sliding distance of $90 \mathrm{~m}$. A neutral salt spray test was conducted to examine the corrosion resistance. The test was conducted in $35^{\circ} \mathrm{C}, 5 \mathrm{wt} \% \mathrm{NaCl}$ solution. The test method referred to the Chinese national standard GB/T 10125-2012 [17], and the judgement of corrosion grade referred to the Chinese national standard GB/T 6461-2002 [18].

\section{Results and Discussion}

\subsection{Surface Morphology of Co-P Coatings}

The surface morphology of Co-P coatings deposited under different currents is shown in Figure 1. As can be seen, the coatings as plated (Figure $1 \mathrm{a}, \mathrm{c}, \mathrm{e}$ ) are dense, smooth and free from pinhole. Coatings deposited under DP (Figure 1e) are smoother than coatings deposited under DC (Figure 1a) and SP (Figure 1c) currents. After annealing at $400{ }^{\circ} \mathrm{C}$ for $30 \mathrm{~min}$, small particles appeared on the surface of all coatings (Figure 1b,d,f), especially on coatings deposited under DC (Figure 1b). The reasons are as follows: The small tips created during deposition could be effectively removed by reverse current under DP current at any time, thus making the surface smoother. When annealing, elemental phosphorus, which originally dispersed in the alloy, was aggregated at the grain boundaries, and Co-P compounds were generated. This transformation broke the homogeneous elemental distribution, which led to the transformation from an amorphous to a crystalline state, thus it formed a relatively rough surface. There were denser and finer grains in the coatings deposited under SP and DP currents, so that they changed less after annealing as compared with those deposited under DC current.

The microtopography of Co-P coatings heat treated at $400^{\circ} \mathrm{C}$ was characterized by TEM (Figure 2). It can be seen that, after thermal treatment at $400^{\circ} \mathrm{C}$, fine and uniform nanocrystalline grain was formed within coatings deposited under direct and pulse currents. The respective grain size of the coatings deposited under DC, SP and DP currents were 12-13 nm, 10-12 $\mathrm{nm}$ and 8-10 nm. It can be ascribed to the fact that pulse current could provide much higher overpotential under the same average current, which could cause a higher nucleation rate than the velocity of grain growth, so it produced more crystal nucleuses. Consequently, the grains were refined [7].

The chemical composition of the coatings was analyzed by EDS. The results showed that the alloy consisted of Co and P. The P content in coatings deposited under DC, SP and DP currents was 9.6, 8.9 and $9.1 \mathrm{wt} \%$, respectively. 


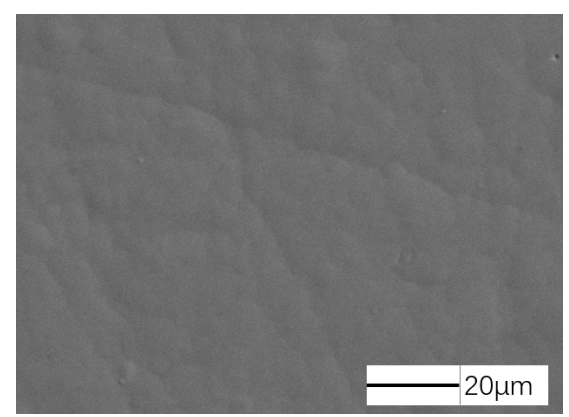

(a)

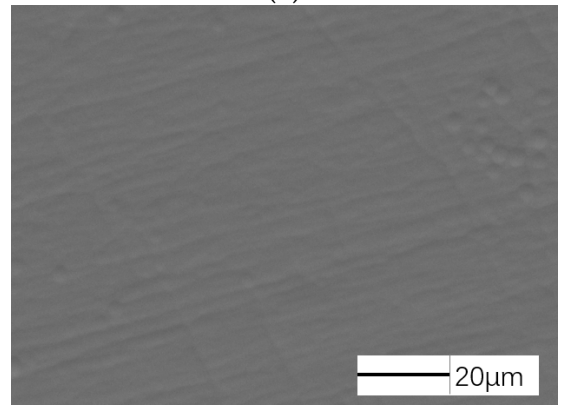

(c)

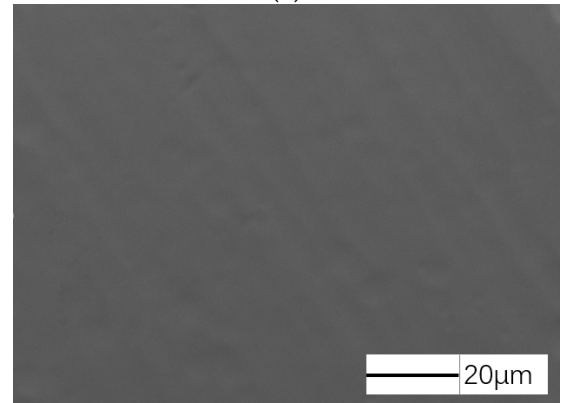

(e)

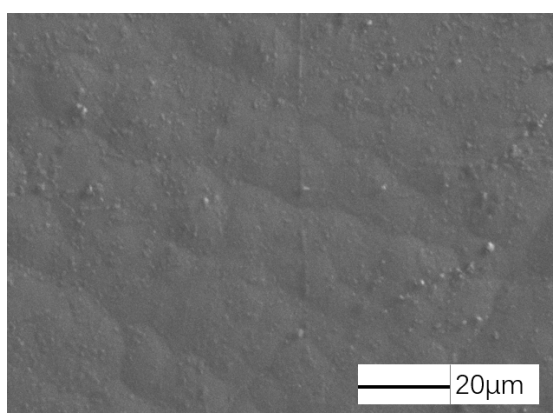

(b)

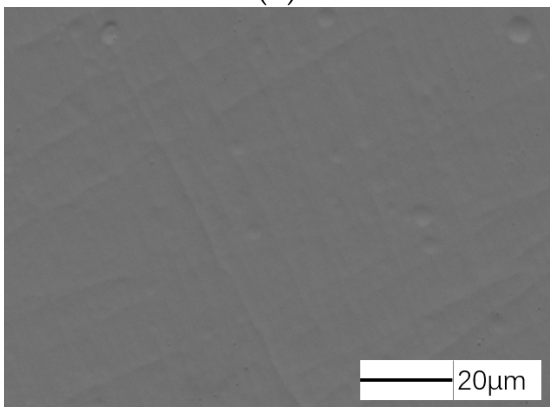

(d)

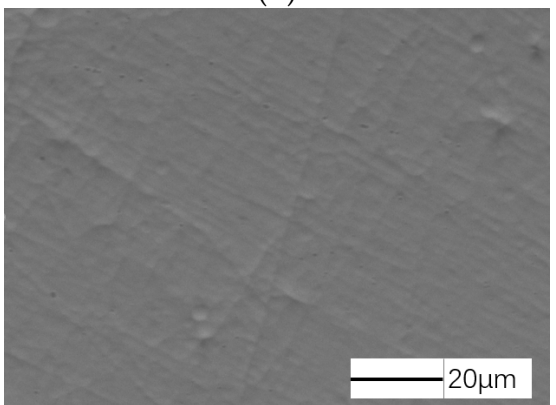

(f)

Figure 1. Micromorphology of coatings deposited under different currents. (a) DC as deposited; (b) DC $400{ }^{\circ} \mathrm{C}$ heat treated; (c) SP as deposited; (d) SP $400{ }^{\circ} \mathrm{C}$ heat treated; (e) DP as deposited; (f) DP $400{ }^{\circ} \mathrm{C}$ heat treated.
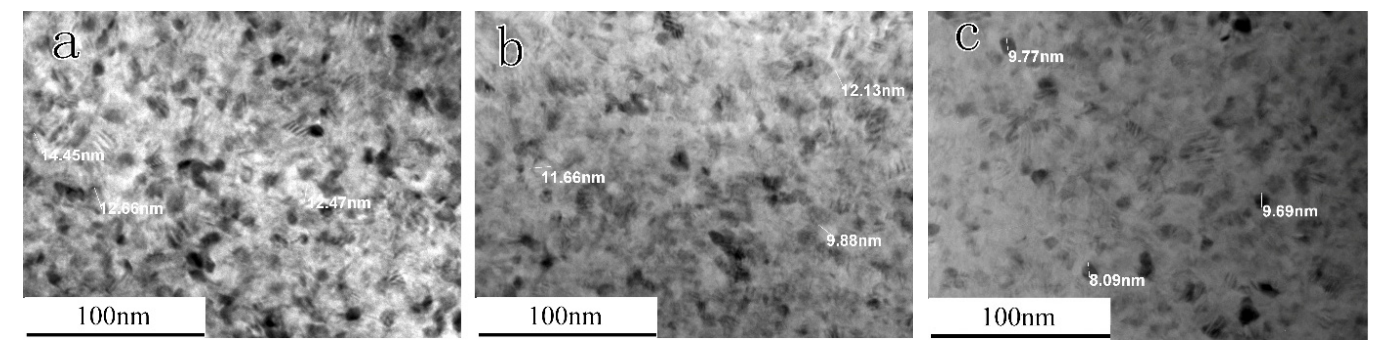

Figure 2. TEM of coatings deposited at different current. (a) DC $400{ }^{\circ} \mathrm{C}$ heat treated; (b) SP $400{ }^{\circ} \mathrm{C}$ heat treated; (c) DP $400{ }^{\circ} \mathrm{C}$ heat treated.

\subsection{Effect of Heat Treatment on the Phase Structure of Co-P Coatings}

The XRD patterns of the coatings deposited under different currents are shown in Figure 3. It can be seen that all coatings showed only one wide peak at $45^{\circ}$ in XRD patterns. After being annealed at $400{ }^{\circ} \mathrm{C}$ for $30 \mathrm{~min}$, all coatings were transformed into a crystalline state, and the peaks of the different coatings appeared in the same position. It meant that the coatings deposited under different currents without any post-treatment were all in an amorphous state, and they transformed into crystalline after 
they were annealed at $400{ }^{\circ} \mathrm{C}$ for $30 \mathrm{~min}$. Furthermore, the crystal structure was not affected by the current waveform. The high content of $\mathrm{P}$ was dispersed in the cobalt metal by breaking the original crystal structure of cobalt metal and forming a supersaturated solid solution. Hence, the Co-P entered an amorphous state [15]. After the heat treatment, the Co-P was recrystallized and the $\mathrm{P}$ was enriched at crystalline grain boundaries [13], while the Co became nanocrystalline.

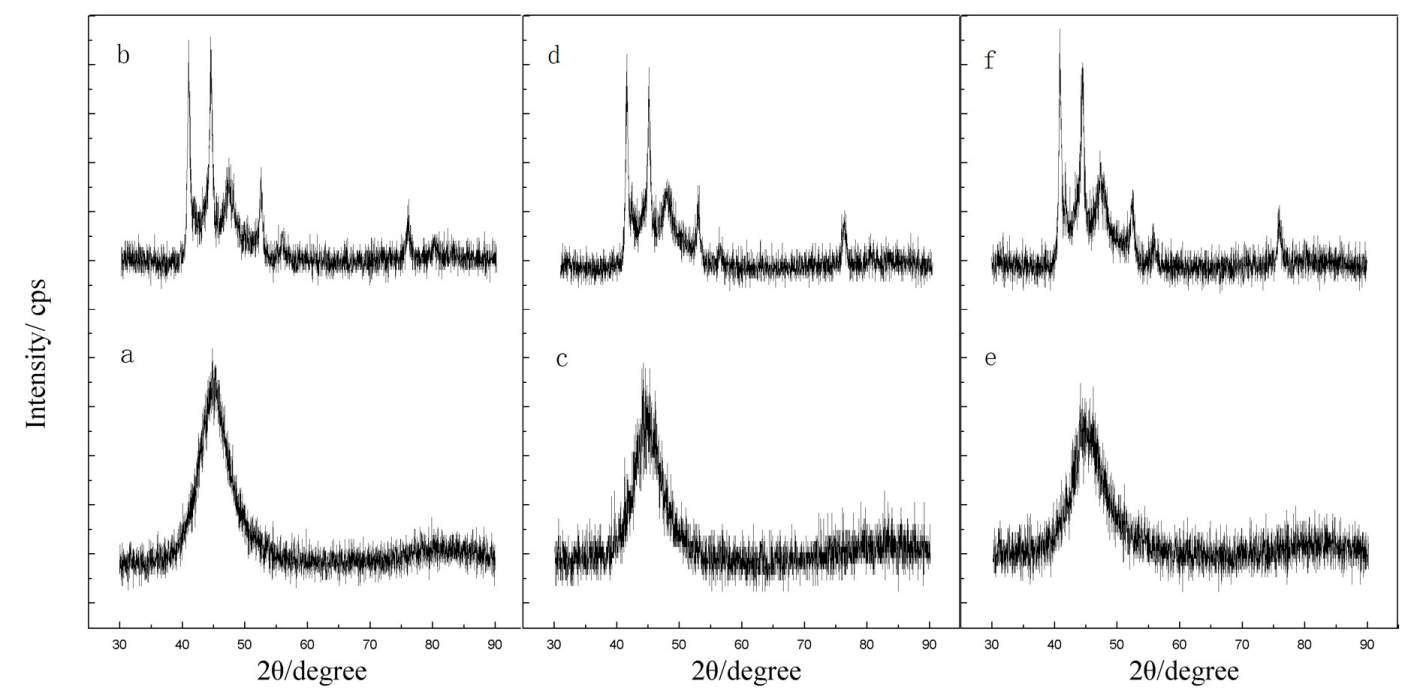

Figure 3. XRD patterns of coatings deposited at different current. (a) DC as deposited; (b) DC heat treated at $400{ }^{\circ} \mathrm{C}$; (c) SP as deposited; (d) SP heat treated at $400{ }^{\circ} \mathrm{C}$; (e) DP as deposited; (f) DP heat treated at $400{ }^{\circ} \mathrm{C}$.

Figure 4 reveals the exact XRD patterns of coatings deposited under DP after heat treatment at different temperatures. As Figure 4 exhibits, after being heated at $300{ }^{\circ} \mathrm{C}$, the XRD patterns of the coatings turned from one wide peak into several peaks. However, the characteristic peaks became sharper and more obvious for the coatings after the heat treatment at $400{ }^{\circ} \mathrm{C}$. The peaks at $41.6^{\circ}, 44.6^{\circ}$, $47.5^{\circ}$ and $76^{\circ}$ in Figure 4c correspond to (100), (002), (101) and (110) planes of a hexagonal close packed (hcp) Co structure individually. Since the phase transformation temperature from hcp-Co to fcc-Co is ca. $417^{\circ} \mathrm{C}$ for hcp-Co, no characteristic peaks of fcc-Co structure can be observed in the patterns [19]. The peaks at $41.0^{\circ}$ and $52.1^{\circ}$ in Figure $4 \mathrm{c}$ corresponding to $\mathrm{Co}_{2} \mathrm{P}$ demonstrated formation of the Co-P compounds during the heat treatment. Not only was the Co-P alloy transformed from amorphous to crystalline, but also the Co-P compounds were formed during the heat treatment.

\subsection{Effect of the Heat Treatment Temperature on Microhardness of Co-P Coatings}

Microhardness, one of the most important performance of Co-P coatings, was tested by a Vickers microhardness tester under a $5 \mathrm{gf}$ load for $10 \mathrm{~s}$, and the indentation depths reached no more than $2.5 \mu \mathrm{m}$, which was much less than the thickness of Co-P coatings. Figure 5 shows the microhardness of coatings deposited under different currents and the heat treatment at different temperatures. It can be seen that the microhardness of Co-P coatings deposited under different currents varied. During the deposition process, the microhardness of coatings deposited under DC, SP and DP currents was 675, 694 and $706 \mathrm{HV}$, respectively. The microhardness of coatings deposited under each current was increased with the heating temperature rising. When the temperature was $300{ }^{\circ} \mathrm{C}$, the hardness of coatings increased to over $1000 \mathrm{HV}$, which reached the level of hard chromium; when the temperature was dramatically increased to $400^{\circ} \mathrm{C}$, the microhardness of coatings deposited under DC, SP and DP currents continued increasing to 1181, 1191 and 1211 HV, separately, which increased by $75 \%, 72 \%$ and $72 \%$ more than the deposited state, respectively. The hardness of Co-P coatings increased after annealing as a result of the formation of $\mathrm{Co}_{2} \mathrm{P}$ and $\mathrm{Co}-\mathrm{P}$ precipitates [20]. 
In addition, coatings deposited under DC, SP and DP currents agreed with the Hall-Petch formula; the smaller the grain size, the higher the microhardness of the nanocrystalline material [21].

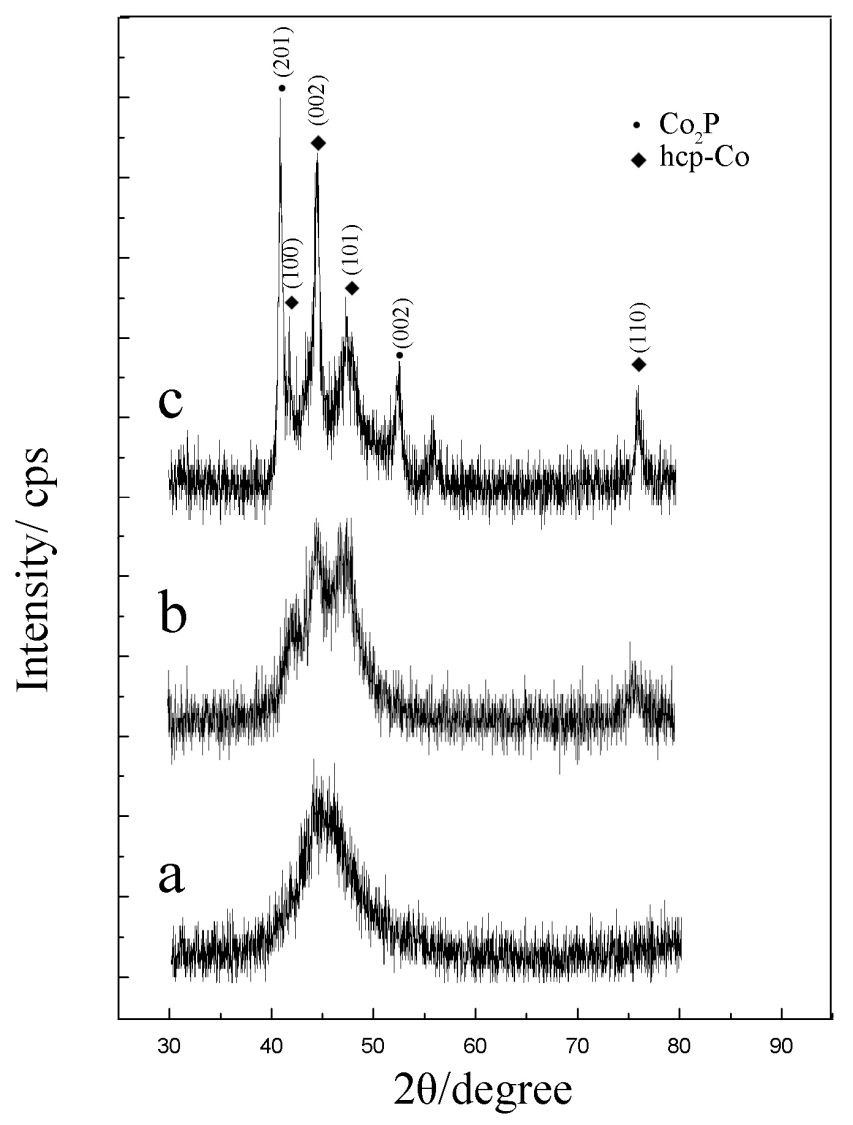

Figure 4. XRD patterns of coatings deposited under DP, heat treated under different temperatures: (a) as deposited; (b) heat treated at $300^{\circ} \mathrm{C}$; (c) heat treated at $400{ }^{\circ} \mathrm{C}$.

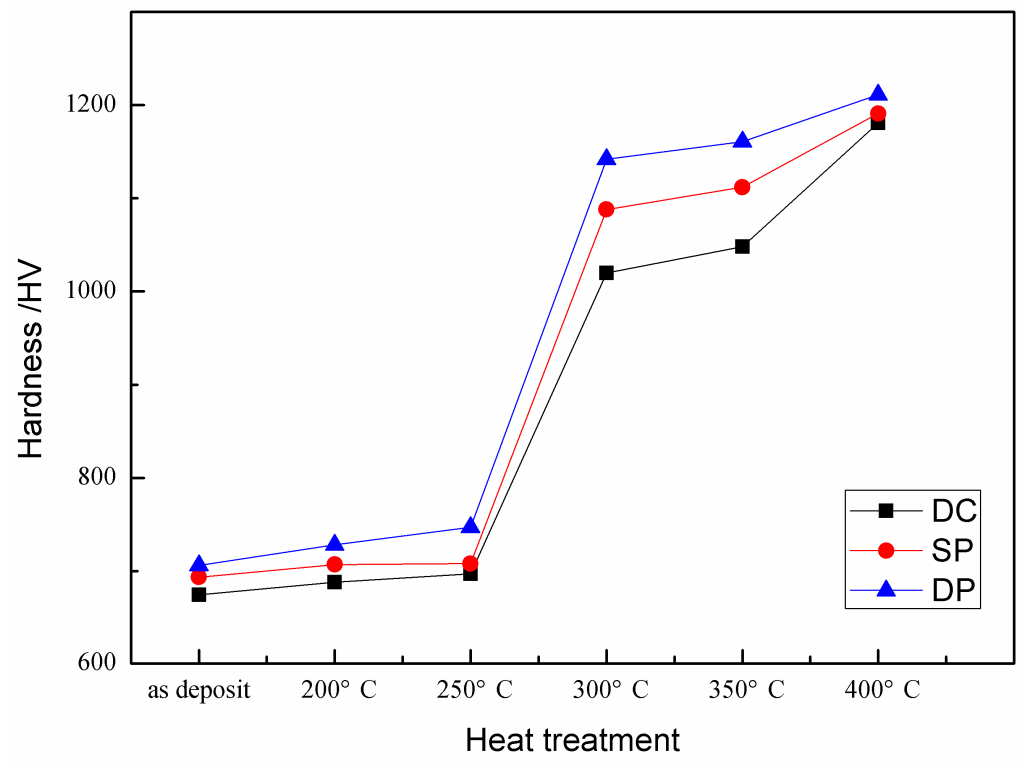

Figure 5. Microhardness of coatings after different heat treatments deposited under different current conditions. 
Figure 6 shows the DSC curve of Co-P coatings deposited under DP from room temperature to $400{ }^{\circ} \mathrm{C}$ at the heating rate of $6{ }^{\circ} \mathrm{C} / \mathrm{min}$ (the DSC curves of Co-P coating deposited under DC and SP currents show the same variation trend). As can be seen, the curve exhibits two exothermic peaks at 299 and $340{ }^{\circ} \mathrm{C}$, respectively. These two peaks corresponded to the crystallization of the deposit and formation of Co-P compounds respectively [15]. Co-P alloy crystallized at ca. $299{ }^{\circ} \mathrm{C}$; at the same time, $\mathrm{P}$ was enriched in grain boundaries; due to the precipitation hardening mechanism, the microhardness of the coatings dramatically increased. When the temperature was up to $340{ }^{\circ} \mathrm{C}$, $\mathrm{Co}_{2} \mathrm{P}$ compounds were formed, and the microhardness increased once again. Both processes could increase the microhardness of the coatings [16]. Consequently, the microhardness of Co-P coatings increased after the heat treatment.

The DSC curve can also explain the XRD patterns of coatings at different temperatures in Figure 4. When the coatings were treated at $300{ }^{\circ} \mathrm{C}$, the alloy started crystallizing, however, the crystallization did not complete. Thus, the XRD patterns were no longer a wide peak, but still no obvious sharp peaks occurred. Co-P compounds did not form at this temperature, therefore, no characteristic peaks appeared in Figure $4 \mathrm{~b}$. However, the crystallization and formation of Co-P compounds were completed. The heat treatment at $400{ }^{\circ} \mathrm{C}$ caused XRD patterns, as shown in Figure $4 \mathrm{c}$, in the form of sharp peaks; the characteristic peaks of Co-P compounds also appeared in the XRD patterns.

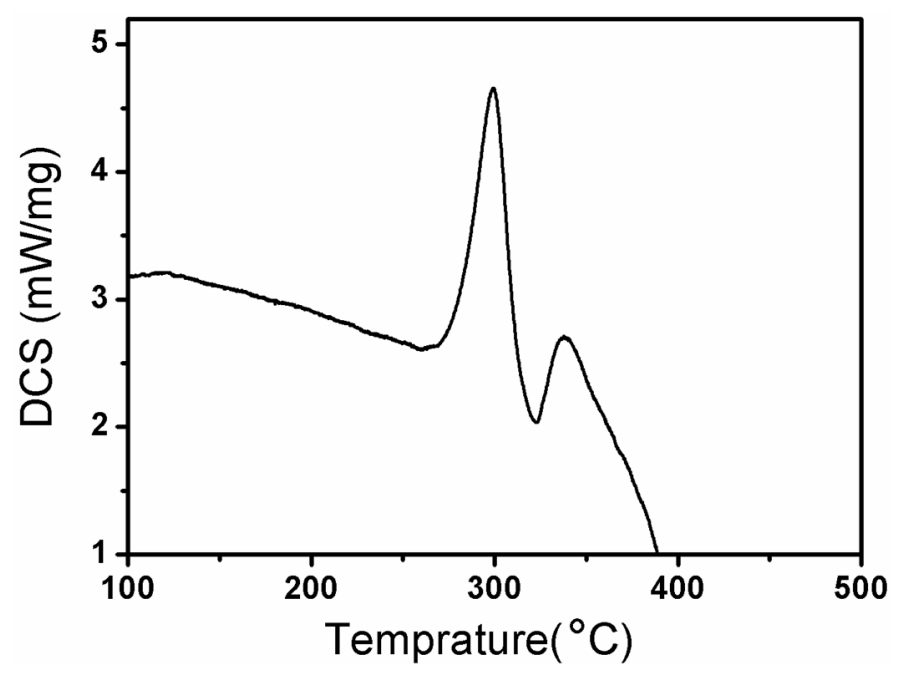

Figure 6. Differential scanning calorimetry (DSC) of DP in air circumstance with a heating rate of $6 \mathrm{~K}$ per minute from room temperature to $400{ }^{\circ} \mathrm{C}$.

\subsection{Effect of Heat Treatment on the Wear Resistance of Co-P Coatings}

Wear rate is one of the most important indicators to measure the wear resistance of the Co-P alloy layer. The wear rate of Co-P coatings deposited under different current and treated at different temperature are shown in Table 2. Samples were tested with the load of $5 \mathrm{~N}, \mathrm{Si}_{3} \mathrm{~N}_{4}$ ball as bearing material.

Table 2. Wear rate of Co-P coating samples deposited under different currents $\left(\mathrm{Si}_{3} \mathrm{~N}_{4}\right.$ ball as bearing material).

\begin{tabular}{|c|c|c|c|}
\hline Current & $\begin{array}{c}\text { As Deposited } \\
\left(10^{-6} \mathrm{~mm}^{3} / \mathrm{N} \mathrm{m}\right)\end{array}$ & $\begin{array}{c}300{ }^{\circ} \mathrm{C} \text { Treated } \\
\left(10^{-6} \mathrm{~mm}^{3} / \mathrm{N} \mathrm{m}\right)\end{array}$ & $\begin{array}{c}400^{\circ} \mathrm{C} \text { Treated } \\
\left(10^{-6} \mathrm{~mm}^{3} / \mathrm{N} \mathrm{m}\right)\end{array}$ \\
\hline $\mathrm{DC}$ & 4.47 & 4.52 & 4.84 \\
\hline $\mathrm{SP}$ & 4.83 & 4.82 & 4.00 \\
\hline $\mathrm{DP}$ & 4.51 & 4.87 & 4.56 \\
\hline
\end{tabular}


In Table 2, the wear rate was $4 \times 10^{-6}-5 \times 10^{-6} \mathrm{~mm}^{3} / \mathrm{N}$ m and changed little no matter how the samples were deposited or treated, and the value was within the measurement error range. The wear rate of coatings was controlled not only by hardness, but also other factors such as microstructure (grain size, crystalline, P concentration [22]). Co-P coatings transformed from amorphous to a nanocrystalline state after heat treatment. The crystallized zones of coatings, having a substantially smaller specific atomic volume than the amorphous matrix, underwent higher tensile stresses, leading to the accelerated nucleation and propagation of microcracks in the crystalline layer, eventually increasing the wear rate of coatings during friction [22]. The second possible reason is that the nanocrystalline structure and Co-P compounds made it easier for the coatings to form hard particles during the wear, rather than only plastic deformation. These particles worsen the abrasive wear. The effect on wear resistance of abrasive wear and improvement of hardness offset each other, resulting in the unchangeable wear rate of the coatings. The wear rate of Co-P coatings deposited under different currents was higher than that of hard chromium $\left(8 \times 10^{-6}-11 \times 10^{-6} \mathrm{~mm}^{3} / \mathrm{N} \mathrm{m}\right.$, with $\mathrm{Al}_{2} \mathrm{O}_{3}$ ball as bearing material) [1,7], and a little higher than that of Co-P coatings deposited by Kosta [7] and Facchini [1] $\left(5 \times 10^{-6}-6 \times 10^{-6} \mathrm{~mm}^{3} / \mathrm{N} \mathrm{m}\right.$, with $\mathrm{Al}_{2} \mathrm{O}_{3}$ ball as bearing material).

\subsection{Effect of Heat Treatment on the Corrosion Resistance of Co-P Coatings}

Corrosion resistance is a key factor to evaluate the nature of Co-P coatings. Corrosion resistance of Co-P coatings deposited under different currents was tested by the salt spray test. The images of samples before and after the test are shown in Figures 7-9. The results showed that no visible corrosion pits appeared on the Co-P coatings ( $40 \pm 2 \mu \mathrm{m}$ thick) deposited under each current after $1000 \mathrm{~h}$ of a neutral salt spray test; only slight gloss reduction occurred on the surface. In comparison, it was reported that hard chromium coatings of about $200 \mu \mathrm{m}$ thickness showed visible corrosion after $1000 \mathrm{~h}$ of a neutral salt spray test [1], and the corrosion index was rated grade 7. Therefore, it could be concluded that the deposited Co-P coatings revealed excellent corrosion resistance. Co-P coatings deposited under each current and treated at 300 and $400{ }^{\circ} \mathrm{C}$ reached the corrosion grade 7-8 and grade 4-5, respectively after $1000 \mathrm{~h}$ test and the results showed slightly better performance than that of hard chromium. In the deposited Co-P coatings, the components of the alloy were dense and uniform, for the reason that $\mathrm{P}$ dispersed in the cobalt metal during the formation of solid supersaturated solution. Thus, the alloy showed higher corrosion potential [10]. Furthermore, in the amorphous coatings of Co-P coatings as deposited, because there were no grain boundaries, the corrosion attacks seem to be lower [20]; thus, Co-P coatings were endowed with outstanding corrosion resistance. When the coatings were heated at $300{ }^{\circ} \mathrm{C}$, the crystallization was finished and $\mathrm{P}$ was enriched in the grain boundaries [13], but Co-P compounds did not form, leading to a decrease in the corrosion resistance of the coatings [20] despite levels remaining high. However, the Co-P compounds were formed after annealing at $400^{\circ} \mathrm{C}$, which decreased the uniformity of the alloy. Furthermore, the Co-P compounds formed microcells with $\mathrm{Co}$, worsening the corrosion resistance of the coatings. Hence, the corrosion resistance of the coatings was reduced. 

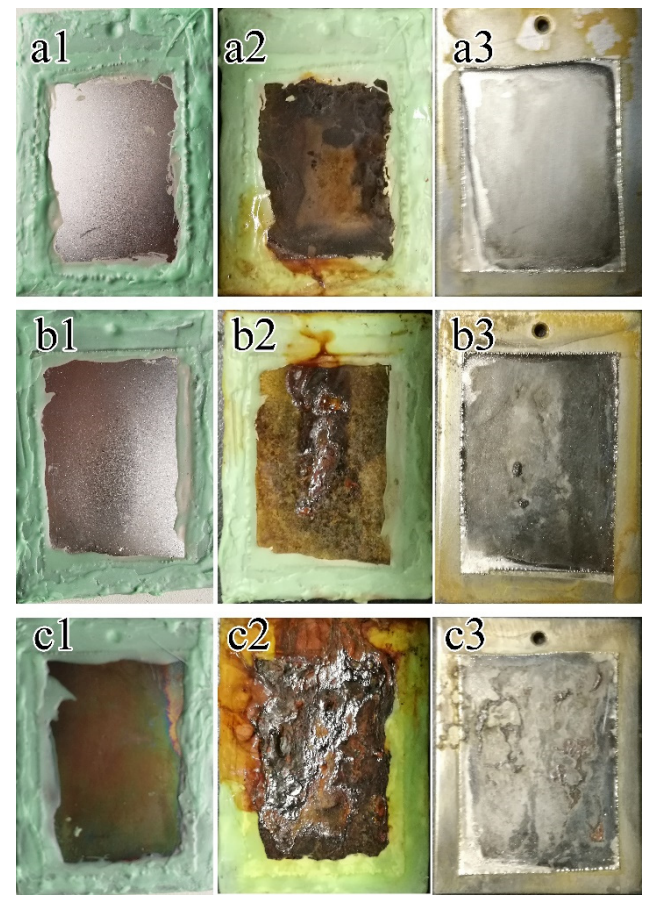

Figure 7. Corrosion results of samples deposited under DC. (a1) as deposited; (a2) as deposited after $1000 \mathrm{~h}$ test; (a3) as deposited with corrosion product removed; (b1) $300{ }^{\circ} \mathrm{C}$ treated; (b2) $300{ }^{\circ} \mathrm{C}$ treated after $1000 \mathrm{~h}$ test; (b3) $300^{\circ} \mathrm{C}$ treated with corrosion product removed; (c1) $400{ }^{\circ} \mathrm{C}$ treated; (c2) $400{ }^{\circ} \mathrm{C}$ treated after $1000 \mathrm{~h}$ test; (c3) $400{ }^{\circ} \mathrm{C}$ treated with corrosion product removed.
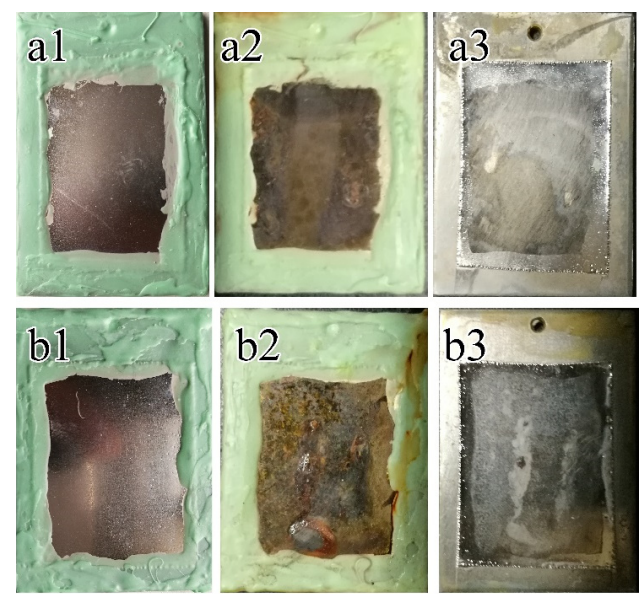

b2
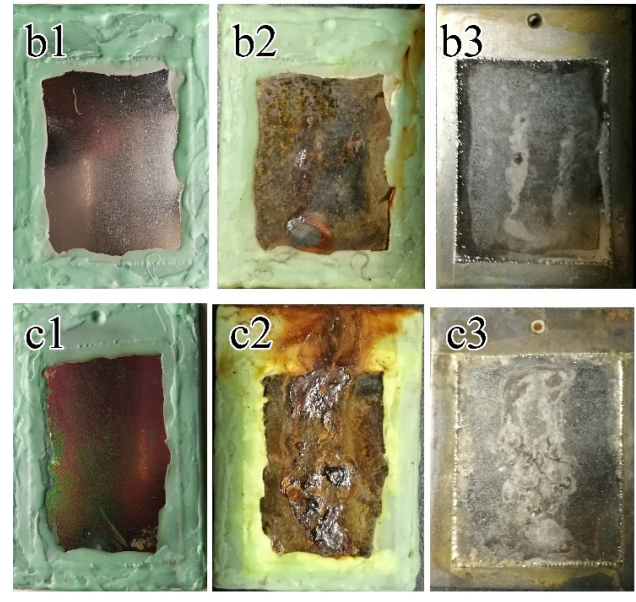

Figure 8. Corrosion results of samples deposited under SP. (a1) as deposited; (a2) as deposited after $1000 \mathrm{~h}$ test; (a3) as deposited with corrosion product removed; (b1) $300{ }^{\circ} \mathrm{C}$ treated; (b2) $300{ }^{\circ} \mathrm{C}$ treated after $1000 \mathrm{~h}$ test; (b3) $300{ }^{\circ} \mathrm{C}$ treated with corrosion product removed; (c1) $400{ }^{\circ} \mathrm{C}$ treated; (c2) $400{ }^{\circ} \mathrm{C}$ treated after $1000 \mathrm{~h}$ test; (c3) $400{ }^{\circ} \mathrm{C}$ treated with corrosion product removed. 

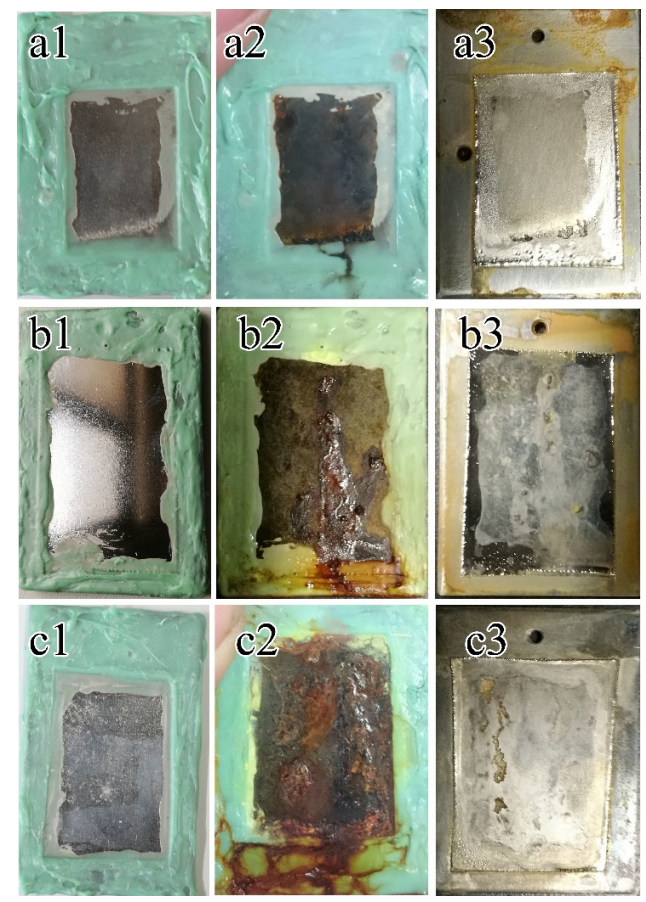

Figure 9. Corrosion results of samples deposited under DP. (a1) as deposited; (a2) as deposited after $1000 \mathrm{~h}$ test; (a3) as deposited with corrosion product removed; (b1) $300^{\circ} \mathrm{C}$ treated; (b2) $300{ }^{\circ} \mathrm{C}$ treated after $1000 \mathrm{~h}$ test; (b3) $300{ }^{\circ} \mathrm{C}$ treated with corrosion product removed; (c1) $400{ }^{\circ} \mathrm{C}$ treated; (c2) $400{ }^{\circ} \mathrm{C}$ treated after $1000 \mathrm{~h}$ test; (c3) $400{ }^{\circ} \mathrm{C}$ treated with corrosion product removed.

\section{Conclusions}

- Smooth and dense Co-P amorphous coatings could be deposited under direct, single pulse and double pulse current respectively on carbon steel substrate, with P content of $9.6,8.9$ and $9.1 \mathrm{wt} \%$, respectively. The coating structure deposited under double pulse current was among the highest in terms of smoothness and density levels.

- Co-P coatings deposited under different currents transformed from an amorphous to hexagonal close packed structure at $299^{\circ} \mathrm{C}$. $\mathrm{Co}_{2} \mathrm{P}$ compounds were formed at $340{ }^{\circ} \mathrm{C}$. Coatings deposited under DC, SP and DP currents became nanocrystalline structures after heat treatment at $400{ }^{\circ} \mathrm{C}$ and the grain size was $12-13 \mathrm{~nm}, 10-12 \mathrm{~nm}$ and $8-10 \mathrm{~nm}$, respectively.

- Under all conditions, the microhardness of the coatings decreased progressively in the order: DP > SP > DC. Microhardness of the coatings deposited under DP was $706 \mathrm{HV}$; it rose to $1211 \mathrm{HV}$ after heat treatment at $400{ }^{\circ} \mathrm{C}$, which was higher than that of hard chromium.

- The wear rate of Co-P coatings was $4 \times 10^{-6}-5 \times 10^{-6} \mathrm{~mm}^{3} / \mathrm{N} \mathrm{m}$, which was lower than that of hard chromium.

- After $1000 \mathrm{~h}$ of a neutral salt spray test, the Co-P coatings deposited under different currents with a thickness of ca. $40 \mu \mathrm{m}$ showed no visible corrosion pits. However, coatings treated at 300 and $400{ }^{\circ} \mathrm{C}$ reached grade $7-8$ and $4-5$, respectively after $1000 \mathrm{~h}$ test. The results were better than those obtained for hard chromium.

Acknowledgments: This study was financially supported by the Aeronautical Science Foundation of China (No. 2012ZE51058).

Author Contributions: Xiaomei Chen, Xiaotian Hu and Jiangang Qian conceived and designed the experiments; Xiaomei Chen, Xiaotian Hu performed the experiments; Xiaotian $\mathrm{Hu}$ and Xiaomei Chen analyzed the data; Xiaomei Chen, Xiaotian Hu wrote the paper.

Conflicts of Interest: The authors declare no conflict of interest. 


\section{References}

1. Facchini, D.; Mahalanobis, N.; Gonzalez, F.; Palumbo, G. Electrodeposition of nanocrystalline cobalt alloy coatings as a hard chrome alternative. In Proceedings of the DoD Corrosion Conference, Washington, DC, USA, 12-14 August 2009.

2. Hazra, S.; Sabiruddin, K.; Bandyopadhyay, P.P. Plasma and HVOF sprayed WC-Co coatings as hard chrome replacement solution. Surf. Eng. 2012, 28, 37-43. [CrossRef]

3. Wasekar, N.P.; Sundararajan, G. Sliding wear behavior of electrodeposited Ni-W alloy and hard chrome coatings. Wear 2015, 342, 340-348. [CrossRef]

4. Houdkova, S.; Zahalka, F.; Kasparova, M.; Berger, L.M. Comparative study of thermally sprayed coatings under different types of wear conditions for hard chromium replacement. Tribol. Lett. 2011, 43, 139-154. [CrossRef]

5. Zhang, J.F.; Liu, M.; Zhou, K.S.; Deng, C.G.; Deng, C.M.; Song, J.B. Tribological behavior of HVOF cermet coatings as alternative to Cr-plating in artificial salt-fog atmosphere. Rare Metal Mater. Eng. 2016, 45, $2492-2497$.

6. Kong, D.J.; Wang, J.C.; Fu, G.Z.; Liu, H. Friction and wear performances of Ni-P coatings by chemical plating after crystallization treatment. Rare Metal Mater. Eng. 2015, 44, 1314-1319.

7. Kosta, I.; Imaz, N.; Cinca, N.; García-Lecina, E.; Sarret, M.; Müller, C. Pulse plated CoP alloy as substitute for hard chromium electrodeposits. Trans. Inst. Metal Finish. 2012, 90, 252-258. [CrossRef]

8. Prado, R.; Facchini, D.; Mahalanobis, N.; Gonzalez, F.; Palumbo, G. nCoP takes the hex out of crome plating products finishing. Prod. Finish. 2012, 77, 14-18.

9. Zeinali-Rad, M.; Allahkaram, S.R.; Mahdavi, S. Effect of $\mathrm{pH}$, surfactant, and heat treatment on morphology, structure, and hardness of electrodeposited Co-P coatings. J. Mater. Eng. Perform. 2015, 24, 3209-3217. [CrossRef]

10. Ezhilselvi, V.; Seenivasan, H.; Bera, P.; Anandan, C. Characterization and corrosion behavior of Co and Co-P coatings electrodeposited from chloride bath. RSC Adv. 2014, 4, 46293-46304. [CrossRef]

11. Kosta, I.; Sarret, M.; Müller, C. Structure, microhardness and corrosion behaviour of nanostructured CoP coatings obtained by direct current and pulse plating. Electrochim. Acta 2013, 114, 819-826. [CrossRef]

12. Silva, M.D.; Wille, C.; Klement, U.; Choi, P.; Al-Kassab, T. Electrodeposited nanocrystalline Co-P alloys: Microstructural characterization and thermal stability. Mater. Sci. Eng. A 2007, 445-446, 31-39. [CrossRef]

13. Choi, P.; Da Silva, M.; Klement, U.; Al-Kassab, T.; Kirchheim, R. Thermal stability of electrodeposited nanocrystalline Co-1.1 at. \% P. Acta Mater. 2005, 53, 4473-4481. [CrossRef]

14. Kosta, I.; Vallés, E.; Gómez, E.; Sarret, M.; Müller, C. Nanocrystalline CoP coatings prepared by different electrodeposition techniques. Mater. Lett. 2011, 65, 2849-2851. [CrossRef]

15. Bera, P.; Seenivasan, H.; Rajam, K.S.; Grips, V.K.W. Characterization of amorphous Co-P alloy coatings electrodeposited with pulse current using gluconate bath. Appl. Surf. Sci. 2012, 258, 9544-9553. [CrossRef]

16. Seenivasan, H.; Bera, P.; Rajam, K.; Parida, S.K. Characterization and hardness of Co-P coatings obtained from direct current electrodeposition using gluconate bath. Surf. Rev. Lett. 2013, 20, 549-555. [CrossRef]

17. GB/T 10125-2012 Corrosion Tests in Artificial Atmospheres-Salt Spray Tests; General Administration of Quality Supervision, Inspection \& Quarantine of the People's Republic of China (AQSIQ); Standardization Administration of the People's Republic of China: Beijing, China, 2012.

18. GB/T 6461-2002 Methods for Corrosion Testing of Metallic and Other Inorganic Coatings on Metallic Substrates-Rating of Test Specimens and Manufactured Articles Subjected to Corrosion Tests; General Administration of Quality Supervision, Inspection \& Quarantine of the People's Republic of China (AQSIQ); Standardization Administration of the People's Republic of China: Beijing, China, 2002.

19. Jung, H.; Alfantazi, A. An electrochemical impedance spectroscopy and polarization study of nanocrystalline Co and Co-P alloy in 0.1 $\mathrm{M} \mathrm{H}_{2} \mathrm{SO}_{4}$ solution. Electrochim. Acta 2006, 51, 1806-1814. [CrossRef]

20. Sheikholeslam, M.A.; Raeissi, K.; Enayati, M.H. Study on corrosion behaviour of nanocrystalline and amorphous Co-P electrodeposits. Trans. Inst. Metal Finish. 2010, 88, 324-329. [CrossRef]

21. Chokshi, A.H.; Rosen, A.; Karch, J.; Gleiter, H. On the validity of the hall-petch relationship in nanocrystalline materials. Scr. Metall. 1989, 23, 1679-1683. [CrossRef]

22. Ganavati, B.; Kukareko, V.A.; Tsybul'Skaya, L.S.; Perevoznikov, S.S. Structural state and tribological properties of Co-P coatings. Phys. Metals Metallogr. 2014, 115, 1037-1045. [CrossRef]

(C) 2017 by the authors. Licensee MDPI, Basel, Switzerland. This article is an open access article distributed under the terms and conditions of the Creative Commons Attribution (CC BY) license (http:/ / creativecommons.org/licenses/by/4.0/). 